\title{
RESPONSE TO "IS THERE ROOM FOR ATTENTIONAL IMPAIRMENTS IN BINGE DRINKING? A COMMENTARY ON CARBIA ET AL. (2018).”
}

Authors: Carina Carbia, Eduardo López-Caneda, Montserrat Corral, Fernando Cadaveira

This is the peer reviewed version of the following article: Carbia, C., López-Caneda, E., Corral, M., y Cadaveira, F.(2019). Response to "Is there room for attentional impairments in binge drinking? A commentary on Carbia et al. (2018)." Neuroscience \& Biobehavioral Reviews, 100, 250-251 doi: 10.1016/j.neubiorev.2019.03.004

This article may be used for non-commercial purposes in accordance with Elsevier and International Behavioral Neuroscience Society terms and conditions for use of self-archived versions. 
Response to "Is there room for attentional impairments in binge drinking? A commentary on Carbia et al. (2018)."

Authors: Carina Carbia ${ }^{a}$, Eduardo López-Caneda ${ }^{\mathrm{b}}$, Montserrat Corral ${ }^{\mathrm{c}}$, Fernando Cadaveira $^{\mathrm{c}}$

${ }^{a}$ APC Microbiome Ireland, Biosciences Building, University College Cork, College Rd, T12 YT20, Ireland

${ }^{b}$ Psychological Neuroscience Lab, Research Center in Psychology (CIPsi), School of Psychology, University of Minho, Campus Gualtar, 4710-057, Braga, Portugal

c Department of Clinical Psychology and Psychobiology, Universidade de Santiago de Compostela, Santiago de Compostela, Campus Universitario Sur, s/n, Galicia, Spain

Corresponding author: carina.carbiasinde@ucc.ie (C. Carbia), eduardo.lopez@psi.uminho.pt (E. López-Caneda), montse.corral@usc.es (M. Corral), fernando.cadaveira@usc.es (F. Cadaveira). 
We would like to thank Lannoy et al. (2019) for their interest in expanding and discussing some points of our systematic review of neuropsychological studies in binge drinkers (BDs) (Carbia et al., 2018b). While we appreciate the commentators' interest in our work, it raises issues that warrant clarification. First, the authors argue that our conclusion regarding the apparent absence of attentional impairments in BDs is premature. This argument is based principally on the statement that our review failed to identify neuropsychological studies that reflected attentional difficulties, in particular Lannoy et al. (2017) (published after the completion of our literature search), Sánchez-Roige et al. (2014) and Scaife and Duka (2009). However, these last two articles were indeed included and extensively discussed in our manuscript.

Following widely known neuropsychological assessment sources (such as Lezak et al., 2012; Strauss et al., 2006), we classified the articles within specific cognitive functions. In particular, Sánchez-Roige et al. (2014) was discussed regarding inhibitory control and self-control and Scaife and Duka (2009) regarding processing speed, working memory, cognitive flexibility and visuospatial memory. Lannoy et al. (2019) have interpreted the executive difficulties reported in these two studies in terms of attentional impairments (e.g. cognitive flexibility as purely attentional shifting abilities). As we state in the limitations paragraph, some of the neuropsychological tasks might be classified in different domains, but an effort has been made to describe the tasks and the cognitive constructs measured in order to facilitate the interpretation of the results. In this sense, we believe that referring to this issue by using "not mentioned" or "not referenced" is incorrect, as all relevant articles available at that moment were properly included, even if the classification of cognitive functions can be debatable. In our view, none of the tasks employed in these two articles are traditionally considered attentional tasks (even though attentional abilities are inherently inseparable from higher-order executive abilities). Therefore, we concluded that there was not strong evidence suggesting sustained (only one study of five reported poor performance in BDs) or selective (one out of five) attentional difficulties, at least at a behavioural level (Carbia et al., 2018b). Far from premature, this was an unbiased analysis of neuropsychological studies that departs from the constraints of theoretical models.

Secondly, the authors discussed the interesting contribution of Lannoy et al. (2017), within the broad framework of attentional networks. They reported behavioural impairments in BDs in executive -and more surprisingly- in alerting attentional networks (also referred to as vigilance or sustained attention) by using the Attention Network Task (ANT). Executive attention involves top-down mechanisms directed to resolving conflicts and, typically, it is studied by conflictrelated tasks such as the Stroop task or the Flanker task (Petersen and Posner, 2012). This network relies mainly on frontal areas (anterior cingulate cortex, prefrontal cortex and anterior insula) and partially overlaps with regions involved in prepotent response inhibition (Petersen and Posner, 2012). Disexecutive problems are the most common neuropsychological phenotypes both in alcoholics and young BDs, however, the term "executive" is a semantic conundrum in which convergent constructs overlap (cognitive control, executive control of attention, etc.). Likely, some of the difficulties that Lannoy et al. (2019) attributed to attention might be an extension of this disexecutive phenotype (such as difficulties in interference control) that we highlighted in the original review. Alterations in more basic attentional processes, such as alerting abilities, should be further investigated as it is in contrast with findings from alcoholics tested on the same task (Maurage et al., 2014). This might be due to divergences from the alcohol continuum hypothesis or to a lower reliability of this index in comparison with the executive index (MacLeod et al., 2010). In addition, separate attentional mechanisms can operate simultaneously which might also account for some of the differences in the literature. Deconstruction of attentional processes and 
alcohol-related alterations deserves further consideration, as Lannoy et al. (2019) correctly emphasized. For this purpose, we agree with the authors that -at the behavioural level- the ANT or even the Dot-probe task could be appropriated tasks, especially if complemented by other techniques such as eye tracking devices or event related potentials (ERPs) in order to disentangle early attentional processes.

Although findings obtained with different techniques were outside the scope of our review, we gladly welcome the discussion in Lannoy's commentary. The study of Correas et al. (2018) mentioned in the commentary- is a good example of the usefulness of other techniques to capture attentional difficulties not manifested yet at the behavioural level. In this magnetoenphalography study, the BD group displayed reduced event-related theta power and dysregulated oscillatory synchrony to task-relevant stimuli in a network dependent on the right inferior frontal cortex and linked to attentional control. However, these alterations occurred in the absence of behavioural difficulties in a sustained and selective attentional task (The d2 Test of Attention). Similarly, electroencephalography (EEG) studies in BDs have shown alterations in brain electrical activity related to attention (N2/P3) using oddball task paradigms, with no between-group differences in task performance (see López-Caneda et al., 2014, for a review). The evidence from EEG findings might be indicative of a neurocompensation phenomenon (augmented amplitude, e.g. LópezCaneda et al., 2013) that gradually evolves towards a deficit (amplitude reduction) with a more intense BD pattern (e.g. Maurage et al., 2012) and, eventually, manifests as a clear impairment (longer latency and reduced amplitude of attentional-related ERP components) in alcoholism (Campanella et al., 2009, for a review).

As outlined by Lannoy and colleagues, little research has been devoted to attention in BDs. The only exception might be the alcohol attentional bias, that is, the effect whereby alcohol cues become motivationally salient at the expense of other stimuli (Field and Cox, 2008). Young BDs appear to display an alcohol attentional bias related to slow processes of maintenance or disengagement of attention from alcohol related stimuli (Carbia et al., 2018a). On the contrary, studies with alcohol dependent patients appear to indicate that alcoholism is associated with an alcohol bias dependent on fast attentional orientation processes (Noël et al., 2006). It is plausible that alcohol bias automatization increases as a function of severity (i.e., top-down towards bottom-up mechanisms) (Noël et al., 2006). A recent study mentioned in the commentary was Herman et al. (2018), in which a high BD score was associated with reduced activation in the areas underlying the ventral attention network (VAN). This network is also referred to as the salience network (particularly, the anterior part of the ventral attention network) and plays a key role in cognitive control by integrating sensory input to attend to relevant stimuli (Peters et al., 2016).

From a network perspective, we believe that rather than purely attentional deficits, the evidence seems to indicate that young BDs have alterations in salience and executive networks that not only continue to be present throughout the addiction cycle but also seem to be a transdiagnostic feature in drug addiction (Zilverstand et al., 2018). We agree that these difficulties are multifaceted in nature (e.g. endogenous versus exogenous) and deserve to be further deconstructed as Lannoy and colleagues highlighted. We appreciate Lannoy's feedback on our manuscript and hope to clarify some misconceptions by emphasizing that -so far- behavioural data is not indicative of broad attentional impairments in BDs according to our comprehensive literature search. Nevertheless, studies focused on identifying difficulties in overlapping

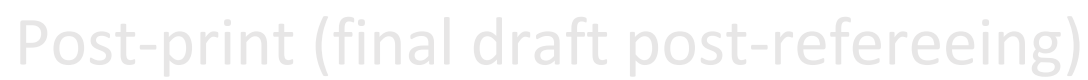


attentional processes are lacking, which limits the existing knowledge and any potential implementation at the intervention level.

\section{Funding}

Carina Carbia has received funding from the European Union's Horizon 2020 research and innovation programme under the Marie Sklodowska-Curie grant agreement No. 754535. Eduardo López-Caneda was supported by the SFRH/BPD/109750/2015 Postdoctoral Fellowship of the Portuguese Foundation for Science and Technology as well as by the Psychology Research Centre (UID/PSI/01662/2013), cofinanced by FEDER through COMPETE2020 under the PT2020 Partnership Agreement (POCI-01-0145-FEDER-007653).

\section{Conflict of Interest Statement}

The authors declare that the research was conducted in the absence of any commercial or financial relationships that could be construed as potential conflicts of interest.

\section{References}

Campanella, S., Petit, G., Maurage, P., Kornreich, C., Verbanck, P., Noel, X., 2009. Chronic alcoholism: insights from neurophysiology. Clin. Neurophysiol. 39, 191-207. https://doi.org/10.1016/j.neucli.2009.08.002.

Carbia, C., Corral, M., Doallo, S., Caamaño-Isorna, F., 2018a. The dual-process model in young adults with a consistent binge drinking trajectory into adulthood. Drug Alcohol Depend. 186, 113-119. https://doi.org/10.1016/j.drugalcdep.2018.01.023.

Carbia, C., López-Caneda, E., Corral, M., Cadaveira, F., 2018b. A systematic review of neuropsychological studies involving young binge drinkers. Neurosci. Biobehav. Rev. 90, 332-349. https://doi.org/10.1016/j.neubiorev.2018.04.013.

Correas, A., López-Caneda, E., Beaton, L., Holguín, S.R., García-Moreno, L., Antón-Toro, L., Cadaveira, F., Maestú, F., Marinkovic, K., 2018. Decreased event-related theta power and phase-synchrony in young binge drinkers during targetdetection: an anatomicallyconstrained MEG approach. J. Psychopharmacol. https://doi.org/10. 1177/0269881118805498. In press.

Field, M., Cox, W.M., 2008. Attentional bias in addictive behaviors: a review of its development, causes, and consequences. Drug Alcohol Depend. 97, 1-20. https://doi. org/10.1016/j.drugalcdep.2008.03.030.

Herman, A.M., Critchley, H.D., Duka, T., 2018. Binge drinking is associated with attenuated frontal and parietal activation during successful response inhibition in fearful context. Eur. J. Neurosci. https://doi.org/10.1111/ejn.14108. In press.

Lannoy, S., Heeren, A., Moyaerts, N., Bruneau, N., Evrard, S., Billieux, J., Maurage, P., 2017. Differential impairments across attentional networks in binge drinking. Psychopharmacology (Berl.) 234, 1059-1068. https://doi.org/10.1007/s00213-0174538-4.

Lannoy, S., Heeren, A., Dormal, V., Billieux, J., Maurage, P., 2019. Is there room for attentional impairments in binge drinking? A commentary on Carbia et al. (2018). Neurosci. Biobehav. Rev. 98, 58-60. https://doi.org/10.1016/j.neubiorev.2019.01.006. 
Lezak, M.D., Howieson, D.B., Bigler, E.D., Tranel, D., 2012. Neuropsychological Assessment, 5th ed. Oxford University Press, New York.

López-Caneda, E., Cadaveira, F., Crego, A., Doallo, S., Corral, M., Gómez-Suárez, A., Rodríguez Holguín, S., 2013. Effects of a persistent binge drinking pattern of alcohol consumption in young people: a follow-up study using event-related potentials. Alcohol Alcohol. 48, 464-471. https://doi.org/10.1093/alcalc/agt046.

López-Caneda, E., Mota, N., Crego, A., Velasquez, T., Corral, M., Rodríguez Holguín, S., Cadaveira, F., 2014. Anomalías neurocognitivas asociadas al consumo intensivo de alcohol (binge drinking) en jóvenes y adolescentes: Una revisión. Addicciones 26, 334359 .

MacLeod, J.W., Lawrence, M.A., McConnell, M.M., Eskes, G.A., Klein, R.M., Shore, D.I., 2010. Appraising the ANT: psychometric and theoretical considerations of the attention network test. Neuropsychology 24, 637-651. https://doi.org/10.1037/ a0019803.

Maurage, P., Joassin, F., Speth, A., Modave, J., Philippot, P., Campanella, S., 2012. Cerebral effects of binge drinking: respective influences of global alcohol intake and consumption pattern. Clin. Neurophysiol. 123, 892-901. https://doi.org/10.1016/j. clinph.2011.09.018.

Maurage, P., de Timary, P., Billieux, J., Collignon, M., Heeren, A., 2014. Attentional alterations in alcohol dependence are underpinned by specific executive control deficits. Alcohol. Clin. Exp. Res. 38, 2105-2112. https://doi.org/10.1111/acer.12444.

Noël, X., Colmant, M., Van Der Linden, M., Bechara, A., Bullens, Q., Hanak, C., Verbanck, P., 2006. Time course of attention for alcohol cues in abstinent alcoholic patients: the role of initial orienting. Alcohol. Clin. Exp. Res. 30, 1871-1877.

Peters, S.K., Dunlop, K., Downar, J., 2016. Cortico-striatal-thalamic loop circuits of the salience network: a central pathway in psychiatric disease and treatment. Front. Syst. Neurosci. 10, 104. https://doi.org/10.3389/fnsys.2016.00104.

Petersen, S.E., Posner, M.I., 2012. The attention system of the human brain: 20 years after. Annu. Rev. Neurosci. 35, 73-89. https://doi.org/10.1146/annurev-neuro- 062111-150525.

Sánchez-Roige, S., Baro, V., Trick, L., Peña-Oliver, Y., Stephens, D.N., Duka, T., 2014. Exaggerated waiting impulsivity associated with human binge drinking, and High alcohol consumption in mice. Neuropsychopharmacology 39, 2919-2927. https:// doi.org/10.1038/npp.2014.151.

Scaife, J.C., Duka, T., 2009. Behavioural measures of frontal lobe function in a population of young social drinkers with binge drinking pattern. Pharmacol. Biochem. Behav. 93, 354362. https://doi.org/10.1016/j.pbb.2009.05.015.

Strauss, E., Sherman, E.M., Spreen, O., 2006. A Compendium of Neuropsychological Tests: Administration, Norms, and Commentary. American Chemical Society.

Zilverstand, A., Huang, A.S., Alia-Klein, N., Goldstein, R.Z., 2018. Neuroimaging impaired response inhibition and salience attribution in human drug addiction: a systematic review. Neuron 98, 886-903. https://doi.org/10.1016/j.neuron.2018.03.048. 